\title{
The use of the Mock-up-Cz physical model in the design of engineered barriers
}

\author{
J. Pacovský \\ Centre of Experimental Geotechnics, \\ Czech Technical University in Prague, Czech Republic
}

\begin{abstract}
A fundamental challenge concerning research into high-level radioactive waste disposal is the construction design of natural and engineered barriers capable of preventing the leakage of hazardous radionuclides over a period of roughly 100 thousand years. In order to obtain the information enabling the design of such a construction, it is necessary to employ all the experimental tools and procedures available including physical modelling. The most relevant model types for this task have been found to be those made at a scale of $1: 1$, referred to as mock-up models. Information on the construction, operation and dismantling of a vertical model of a bench-scale buffer mass test of Czech smectitic clay employing the KBS-3V system modification forms the main subject matter of this paper.

Keywords: radioactive waste, engineered barrier, bentonite block, Mock-up-Cz experiment, dismantling procedures.
\end{abstract}

\section{Introduction}

Solving the problem of the safe isolation of radioactive waste requires a multidisciplinary approach. It is generally accepted that underground repository waste isolation must be assured by a multi-barrier system consisting of the container with the high level radioactive waste itself, an engineered barrier currently intended to be based on bentonites - and a natural barrier formed by a suitable rock environment.

As part of the research into engineered barriers based on highly compacted bentonite blocks, a physical model called Mock-up-Cz, was built at the Centre of Experimental Geotechnics, CTU in Prague from 2000 to 2002, and operated from May 2002 to January 2006. In February 2006, dismantling commenced 
which lasted a total of 47 days. The multidisciplinary research of all the samples taken from the bentonite barrier has been underway since March 2006. A full evaluation of the experiment will be available by the end of 2007 .

\section{Design and construction of Mock-up-Cz}

Mock-up-Cz took the form of a vertical model of a bench-scale buffer mass test of Czech smectitic clay. It was a long-term experiment which aimed to model the behaviour of a sealing barrier composed of highly compacted blocks.

\subsection{Basic description}

The model was placed in an underground test silo with dimensions of $3 \times 3 \times 3 \mathrm{~m}$. The Mock-up-Cz model itself consisted of a steel tank or tube with an inside diameter (d) of $800 \mathrm{~mm}$, a height of $2240 \mathrm{~mm}$ and a wall thickness of $8 \mathrm{~mm}$. The system was designed to withstand an internal pressure of up to $5 \mathrm{MPa}$, fig. 1 .

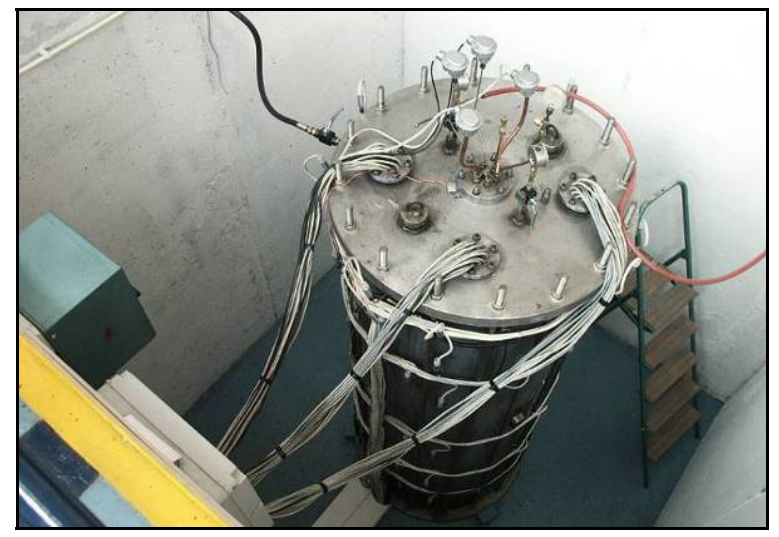

Figure 1: $\quad$ Mock-up-Cz experiment.

The vessel containing high-level radioactive waste was simulated by using a heater placed in an experimental bin. The heating mode was fully automated, and the temperature range could be set between $20^{\circ} \mathrm{C}$ and $300^{\circ} \mathrm{C}$.

\subsection{Buffer material}

Based on an evaluation of research into Czech bentonite, the most appropriate buffer material was found to be a mixture of treated bentonite (from the Rokle deposit), silica sand and graphite [1]. Sand was added in order to facilitate the control of the swelling abilities and plasticity of the mixture. Graphite was added to the mixture to increase its thermal conductivity so that the heat produced by the container was more easily redistributed towards the natural barrier. The basic mixture contained $85 \%$ bentonite, $10 \%$ silica sand and $5 \%$ graphite. 


\subsection{Hydration system}

The potential inflow of granitic water from the natural barrier was simulated by using a flooding system installed on the inner side of the bin featuring two concentric filters, the one closer to the bin being coarse-meshed and the other having voids of less than $100 \mu \mathrm{m}$. Water was let in through four vertical perforated tubes. A hydration system which allowed an increase in hydration pressure of up to $1 \mathrm{MPa}$ was placed outside the experimental silo. Synthetic granitic water was used for saturation; the amount of water and the saturation rate were continuously recorded.

\subsection{Model instrumentation}

The Mock-up physical model was equipped with 52 thermometers, 50 hydraulic pressure cells, 37 humidity sensors of varying construction and 20 resistive tensometers. Temperature, swelling pressure and hydration measurements were taken continuously at six measurement profiles, fig. 2 .
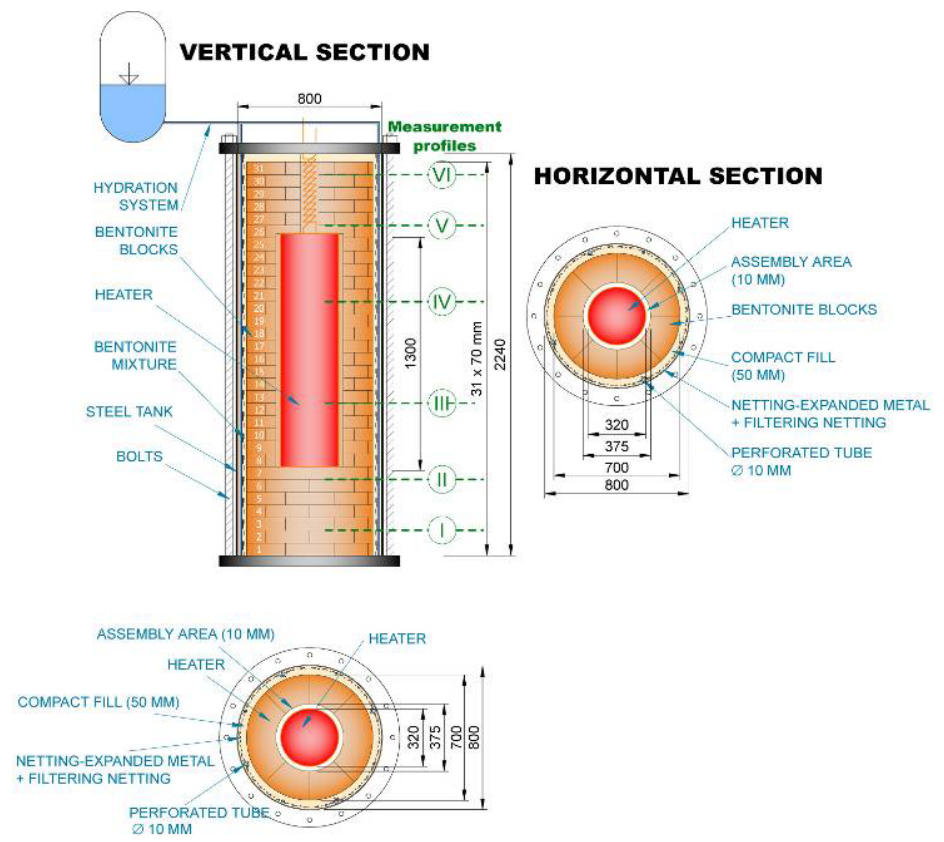

Figure 2: Vertical and horizontal scheme of Mock-up-Cz.

The whole system of registration, evaluation and transfer of data was based on the use of a small portable AD-SYS data logger connected to a CEG server.

The measurement of changes in moisture content using sensors was the most difficult and financially the most demanding of all the basic measurements of the various geotechnical parameters. Due to the notoriously inconsistent nature 
of the results of moisture content measurement provided by sensors, an alternative method for monitoring on-going saturation was sought from the very launch of the experiment. This resulted in a decision to combine automated measurement using sensors with regular core sampling (drilling) used for the gravimetric evaluation of the moisture content.

\section{Experimental procedures}

The Mock-up-Cz was designed as a long-term experiment. Following consultation with foreign experts, the experiment was divided into 3 operational phases followed by the dismantling phase and final post mortem analysis [2].

\subsection{Phase 1}

The filter was kept dry and the power switched on to reach a maximum temperature within the bentonite of $90 \pm 5^{\circ} \mathrm{C}$. Temperature, swelling pressure and hydration recordings were taken continuously for 6 months. Buffer evolution in Phase 1 consisted of a redistribution of initial pore water as a result of the thermal gradient across the buffer and the homogenisation and subsequent consolidation of the filling mixture due to the swelling pressure exerted by the hydrating and expanding blocks.

\subsection{Phase 2}

Power to the heater was maintained at a constant level and the filter filled with synthetic granitic water by connecting two of the perforated pipes to a water reservoir and using the other two for air release. Temperature, swelling pressure and hydration recordings were taken continuously as the buffer evolved towards a state of full water saturation.

Core samples were taken at pre-set intervals throughout this phase in order to physically determine saturation progress and the effect of the various processes at work on the permeability and swelling capacity of the bentonite mixture.

\subsection{Phase 3}

Saturation and temperature loading of the buffer by the heater were stopped during this phase. When the heater was switched off, the cooling phase commenced which lasted approximately 2 weeks.

\subsection{Dismantling and post-mortem analysis}

The dismantling process was conducted according to a detailed timetable and included the following:

1 scientific programme (tests and analysis on samples)

2 sampling plan (location and specific requirements of each sample)

3 scenario (guidelines and procedures for dismantling and sampling operations, work organisation as well as records and documents)

Detailed tests focused on the filling material, corrosion and instrumentation. 


\section{Selected results from the experiment}

\subsection{Phase 1}

Loading the barrier with temperature (before the introduction of external water) caused a redistribution of the original moisture content. In the vicinity of the heater, the moisture content dropped from the original $8-10 \%$ to $2 \%$, while, conversely, in those areas more remote from the heater, it rose to a maximum of $22 \%$. Exact moisture content distribution on completion of the redistribution process was determined by analysing the moisture content of core samples.

Together with a redistribution in moisture content, a new equilibrium temperature gradient was created.

\subsection{Phase 2}

After the commencement of the saturation process, swelling pressure inside the experimental bin gradually increased. The swelling bentonite blocks gradually filled in all the empty spaces within the bentonite barrier (joints and technological gaps). This led to a reduction in the original volume density of the highly compacted blocks thus accounting for the unexpectedly low swelling pressure results at this stage in the experiment. Maximum measured swelling pressure reached a value of approximately $2 \mathrm{MPa}$ as compared to the input swelling ability of the blocks of $4 \mathrm{MPa}$, fig. 3 .

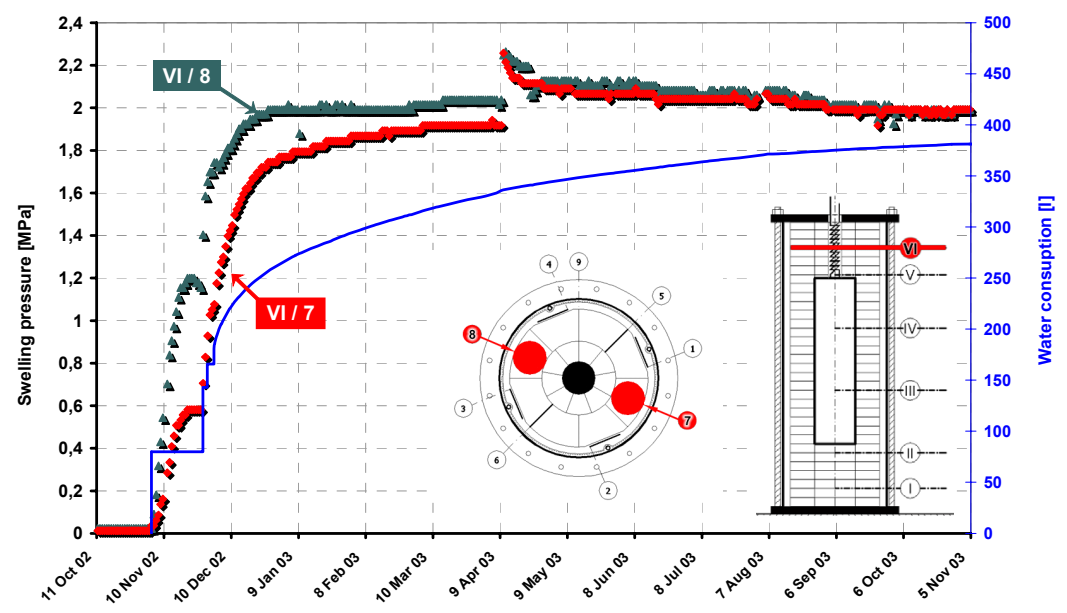

Figure 3: Maximum measured swelling pressure.

On-going saturation increased the barrier's thermal conductivity so that the maximum temperature within the barrier fell (from $95^{\circ} \mathrm{C}$ to $85^{\circ} \mathrm{C}$ ) even though heater output remained constant.

Barrier sampling, which took place at regular intervals (by means of core drilling), allowed the precise determination of the saturation process. An analysis 
of samples subsequently revealed that practically complete saturation of the barrier $\left(\mathrm{S}_{\mathrm{r}}=0.9\right)$ was reached 780 days after the initiation of the saturation process, fig. 4 [3]. Phase 2 continued until the end of 2005.

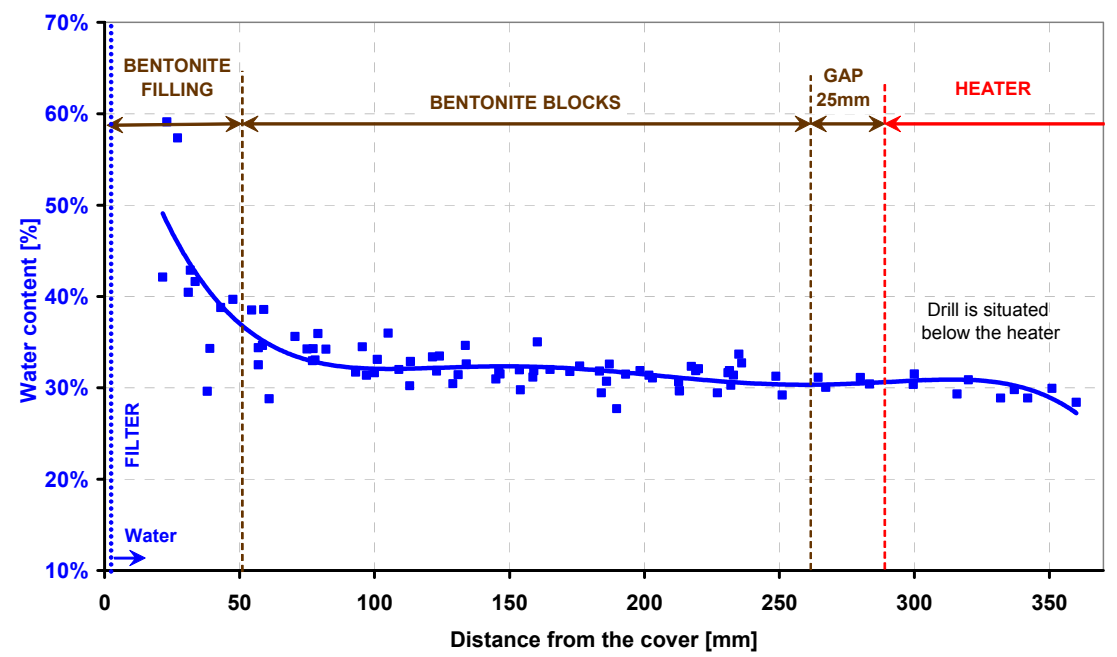

Figure 4: Water content redistribution after 24 months saturation - Oct 2004.

\subsection{Phase 3}

The experimental heater was switched off on 3.1.2006, and the saturation medium inlet was left open for the entire cooling period. Measurements of temperature decrease and changes in swelling pressure were taken continually during Phase 3.

\section{The Dismantling project}

The originally mono-disciplinary (geotechnically oriented) Mock-up-Cz experiment was more successful than any of those involved dared hope and was set to provide a wealth of important data and experience. Consequently, at the beginning of 2005, it was agreed with the principal sponsor of the experiment (RAWRA - The Czech Radioactive Waste Repository Authority) that the final part of the experiment, i.e. dismantling and post-mortem analysis, would be carried out on a multidisciplinary basis. It was agreed that in addition to the CEG CTU in Prague, the final phases would be performed with the participation of the Institute of Chemical Technology in Prague, the Faculty of Science - Charles University in Prague and Masaryk University in Brno. Geotechnical research was extended to include geochemical, corrosion, bacteriological and microscopic research.

In conjunction with these partners, CEG designed a detailed dismantling project which included a sampling plan which took into account the various individual research areas and a detailed time schedule. 
The dismantling process itself commenced on 30th January 2006 with the opening of the experimental bin. The full dismantling of the bentonite barrier, the taking of samples and the extraction of the heater, measuring gauges and cabling was completed on 17th March 2006.

\section{Selected results from post-mortem analysis}

Extensive multidisciplinary research commenced during the dismantling stage the results of which will provide information on the rheological stability of an engineered barrier consisting of highly compacted blocks moulded from a mixture based on Czech bentonite (Rokle deposit).

The results of liquid limit tests on the barrier material and a full evaluation of changes in volume densities are just two of the interesting sets of results obtained to date.

\subsection{Changes in liquid limit $w_{L}$ of barrier material}

One of the most significant characteristics of the bentonite-based barrier material is its high plasticity. In soil mechanics, material plasticity (plastic material behaviour) is defined as the range of moisture content values between the liquid limit $\mathrm{w}_{\mathrm{L}}$ and the plasticity limit $\mathrm{w}_{\mathrm{P}}$ (Atterberg limits). The distance between these limits specifies by how many percent the moisture content of the material at the plasticity limit may be increased so that it will still behave as a plastic material. It generally holds true that the higher the plasticity index of a material, the more suitable it is for use in an engineered barrier. This material remains plastic even after a considerable increase in moisture content, and is easily able to fill all the discontinuity faults (gaps, joint, cracks).

Research of the rheological stability (Atterberg limits) of the Mock-up-Cz experiment was aimed at verifying whether the long-term thermal stress from the heater acting on the barrier, accompanied by barrier saturation, causes material degradation and thus a decrease in plasticity signalled primarily by a decrease in the liquid limit $\mathrm{w}_{\mathrm{L}}$.

Fig. 5 shows the decrease in the liquid limit in relation to long-term temperature effects. Individual sections of the bentonite barrier were loaded with various temperatures depending on the distance from the heater for a period of over 3 years. The effect of a temperature of $77^{\circ} \mathrm{C}$ caused a decrease in the liquid limit from the original $160 \%$ to $110 \%$. As the plasticity limit tends to show only minimum variations, the decrease in plasticity (plasticity index) can be stated as being approximately $50 \%$. It will require the results of additional tests (permeability, swelling ability, mineralogy etc.) to show whether extensive material degradation has occured in this case.

\subsection{Changes in the input dry density $\rho_{d}$ of the barrier material}

A further important characteristic of the barrier material is its swelling ability. In contact with water, bentonite swells, filling up any gaps and sealing discontinuity faults. The commonly accepted swelling pressure value required of barrier 


\section{Management of Natural Resources, Sustainable Development and Ecological Hazards}

material ranges from 5 to $10 \mathrm{MPa}$. In order to obtain such high swelling ability, natural bentonite must be compacted into so-called prefabricates. The dry density of compacted prefabricates ranges from $1700-1800 \mathrm{~kg} / \mathrm{m}^{3}$ (the dry density of the natural material is around $1200 \mathrm{~kg} / \mathrm{m}^{3}$ ). The swelling ability of bentonites, therefore, largely depends on their dry density, fig. 6 .

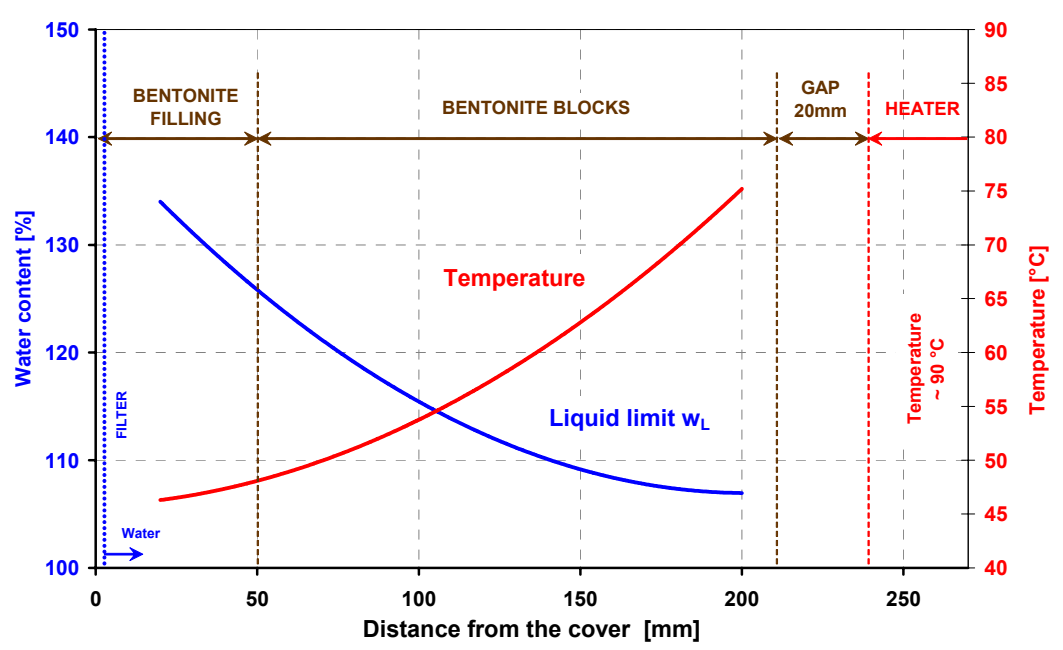

Figure 5: Decrease in liquid limit due to long-term heating.

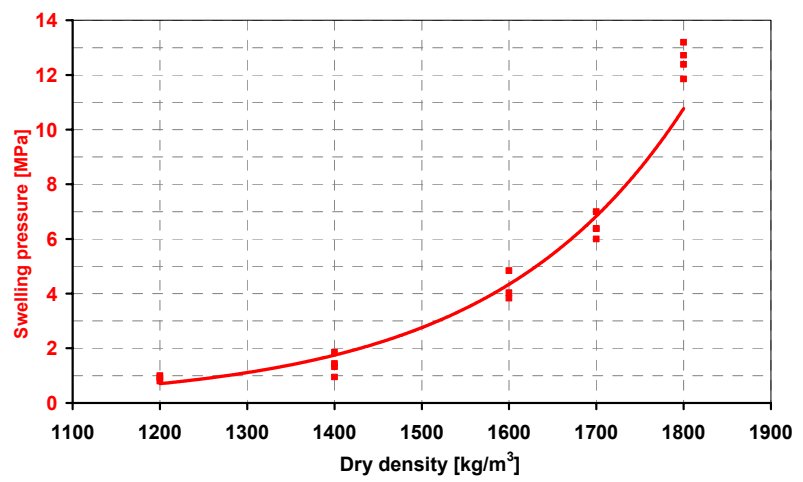

Figure 6: Swelling ability of natural Rokle bentonite in relation to dry density.

Unless compacted bentonite (highly compacted block) is allowed to expand into empty spaces, it exerts a maximum swelling pressure of 5 to $10 \mathrm{MPa}$. All the experimental barriers to date, however, have, to a greater or lesser extent, contained construction joints between the prefabricates, technological gaps for operating the heater etc. The smaller the number of discontinuity faults, the higher the swelling pressure exerted by the prefabricate and the higher the pressure by which existing joints, cracks etc. are sealed. 
Prefabricates for the Mock-up-Cz experiment were designed so that their swelling pressure would not exceed 5MPa (for reasons of the safety of the experimental bin). The maximum swelling pressure measured, however, only slightly exceeded $2 \mathrm{MPa}$. Furthermore, the swelling pressure in the experimental bin of the Mock-up-Cz experiment displayed a highly non-uniform distribution pattern, even after reaching maximum saturation level.

The very first dry density test results showed considerable decreases in the original dry density; this corresponded to the lower swelling pressure values measured, fig. 7 .

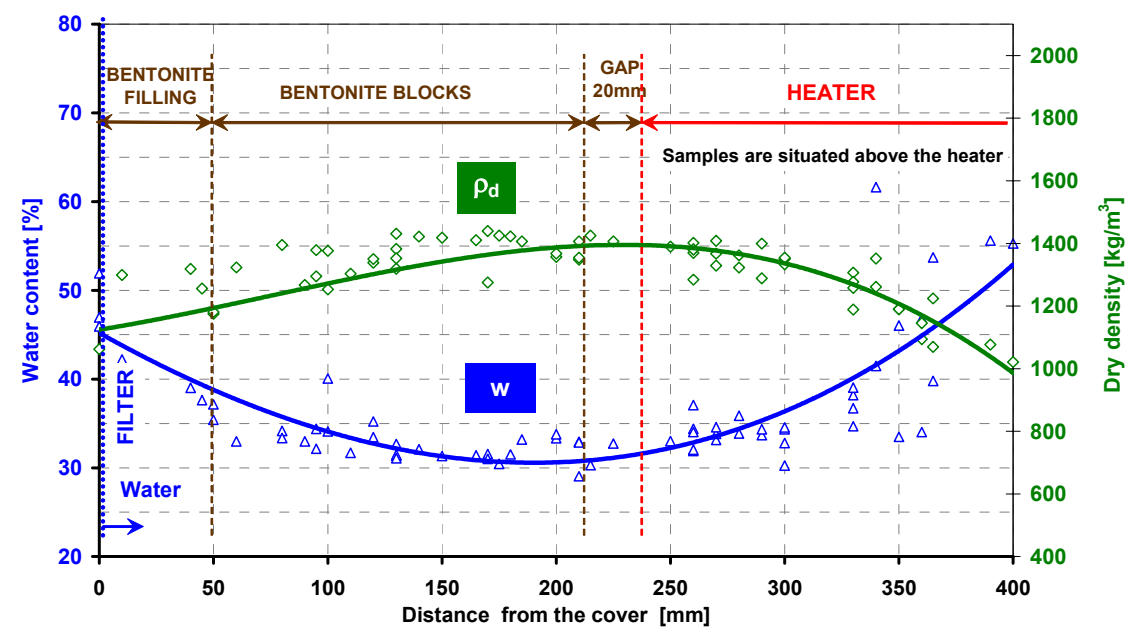

Figure 7: Changes in dry density along the barrier profile after its saturation.

\section{Conclusion}

The Czech Republic joined international research on methods of isolating radioactive waste only after 1990 . Thanks to assistance particularly from the International Atomic Energy Agency in Vienna and the European Community, Czech institutions have been asked to participate in numerous international projects through which they have been able to familiarise themselves with the research results from experiments carried out at various foreign institutions. The Mock-up-Cz experiment benefited greatly from the assistance of foreign, particularly Swedish and Belgian, experts (SKB Sweden, SCK.CEN Belgium).

Mock-up-Cz is the first large-scale Czech experiment aimed at studying the behaviour of bentonite-based engineered barriers. The original intention was to obtain new experience in this highly specialised research field and create a team of young Czech experts. Results from both the construction and performance of the experiment, however, have exceeded all expectations. Consequently, a decision was made in 2005 to include other research areas in this initially monodisciplinary geotechnical experiment. Further, the experiment, which has been 
highly praised by foreign institutions, should result in a confirmation of the suitability of Czech bentonites for the isolation of radioactive waste. A full evaluation of all the stages of the Mock-up-Cz experiment will be completed by the end of 2007.

\section{Acknowledgement}

The experiment could not have taken place without the support of the CTU Faculty of Civil Engineering, Prague - CIDEAS and RAWRA.

\section{References}

[1] Pacovský, J., Selected Results from Geotechnical Research on Bentonite. Proc. of the $8^{\text {th }}$ Int. Conference on Radioactive Waste Management and Environmental Remediation, eds. R. Trávníček \& R. Vašíček, The American Society of Mechanical Engineers ASME, Bruge, session 44, pp.1 - 5, 2001.

[2] Pacovský, J., Experimental Research on Engineered Barriers. Proc. of $4^{\text {th }}$ Int. Symposium on Environmental Aspects in Civil Engineering Education, Formacao Contínua e Publicacoes do Departamento de Engenharia Civil da FEUP, Porto, pp.14-20, 2002.

[3] Pacovský, J., Saturation Development in the Bentonite Barrier of the Mock-up-Cz Geotechnical Experiment. $2^{\text {nd }}$ Int. Meeting Clays in Natural \& Engineered Barriers for Radioactive Waste Confinement, eds. J. Svoboda \& L. Zapletal, Andra Agence nationale pour la gestion des dechets radioactifs, Tours, pp.69 - 70, 2005. 